\title{
A MULTI-DIMENSIONAL POLICY FRAMEWORK FOR ANALYZING AND RESPONDING TO GLOBAL ECONOMIC CRISES
}

\author{
Octavian MOLDOVAN \\ Research assistant, Department of Public Administration and Management, Faculty of Political, \\ Administrative and Communication Sciences, Babes-Bolyai University, Romania. \\ David BARNES \\ PhD candidate, School of Public Policy and Administration, University of Delaware, USA.
}

\begin{abstract}
This paper builds a Holistic Evaluative Model (or HEM) to analyze crises responses, focusing on multiple narratives (explanations) from fields as varied as economics, political science, finance and public policy. A broader framework equips policymakers with more options to shape responses to crises which routinely occurred during the last 75 years of heightened globalization. A HEM reflects the actual process of policy evaluation by combining data across different fields with a valid approach clear enough to discuss increasing opportunities to ameliorate crisis impacts. Even if they are identified, policymakers may not directly influence the causes of crises, which for 2007-2009 included (a) limited market corrections; (b) regulation deficiencies (c) systemic risks; (d) irrational behaviors; (e) informational complexities and $(f)$ cultural failings (that exacerbated these inefficiencies), but they can focus on developing and implementing adequate policy responses. As such, HEMs increase options over a siloed approach by incorporating multiple theoretical tools, dynamic ripple-effects and diverse stakeholders simultaneously evaluating monetary-fiscal policy, actor rationality, systematic risk and the cultural context.
\end{abstract}

KEYWORDS: Holistic Evaluative Model, economic crisis, policy model, globalization.

JEL Classification: G01, G18, H12

\section{Introduction}

In response to the global economic crisis of 2007-2009, policymakers faced complex dilemmas, as institutions were failing, economies collapsing and politics shifting. Even if root causes, which are disputed within and between the literature of various fields such as political science, economics and finance, had been clearly known at the time, the set of effective responses available to policymakers around the world was limited. As policymakers wrestle with the complexities of global crises and possible effective responses, their analysis can benefit from an explanatory model that incorporates economic, behavioral, systematic and cultural factors from diverse fields of study. This paper proposes such a multi-dimensional framework for evaluating crises and responses: namely a Holistic Evaluative Model (or HEM).

Unique to the literature, this paper also proposes two simple and seemingly unrelated policies which combined as a Primary Policy Vector (PPV) to cause the 2007-2009 global economic crisis. Without the PPV, the crisis may not have occurred, been as severe or lasted so long. This catalyst (PPV) was not just national risky mortgage derivatives or banking regulations and even if this 
PPV was the crisis' cause and had been known, it was beyond the control of most policymakers. Therefore, proposing a PPV demonstrates the useful of a broader policy analysis (a HEM) because even if the causes of a crisis are identified, policymakers need ameliorating tools they can influence.

Based on the literature, this paper proposes that the 2007-2009 global crisis was caused by a combined manipulation of US short-term interest rates and Chinese exchange rates. If true, these two policies formed a PPV out of the control of most policymakers worldwide, even in the countries of origin, as they united into a single vector to catalyze the crisis. Rapid reductions in short-term US fed fund rates and excessive foreign reserves generated from artificially low Chinese exchange rates worked in tandem to build pressure on financial markets. That pressure erupted in Mortgage-Backed Securities like a lava flow that emerges at the weakest point of the crust after building from underlying pressure far from the volcano. While acknowledging the complexity of this crisis and the underlying factors of lax subprime underwriting and government regulations, exotic new investment instruments, and complications in liquidity linkages within financial institutions and worldwide - only two components comprised the crisis PPV: (i) unusually steep reductions in short-term federal fund rates which approached zero in a matter of months from late 2007 and (ii) suppression of Chinese exchange rates which over-inflated trade imbalances that produced elevated levels of Asian foreign reserves. Those reserves sought higherreturns than the typical safe vehicle of short-term Treasuries and fled to the seemingly safe (presumably) US-backed mortgage securities (MBS). Pressure from that flow revealed faults in the MBS derivative markets but was fundamentally caused by manipulation of the market equilibrium prices of US Federal Reserve fund rates and Chinese exchange rates.

If these two policies (along with mortgage-back derivatives) did combine into a PPV to cause a "perfect storm", most policymakers even in the US and China, had no control over them. So even if the 2007-2009 global economic crisis was caused mainly by two or three policies acting in tandem to form a causal PPV, most countries affected would not have been able to use this information to affect those policies. Therefore, this paper offers a HEM to evaluate economic crises on four dimensions in which policymakers operate. Our proposed HEM framework in Figure 1 includes:

(1) a fiscal-monetary policy axis,

(2) a rational-irrational actor axis,

(3) a systematic risk-reward axis, and

(4) the cultural context.

Figure 1: Proposed Holistic Evaluative Model (HEM)

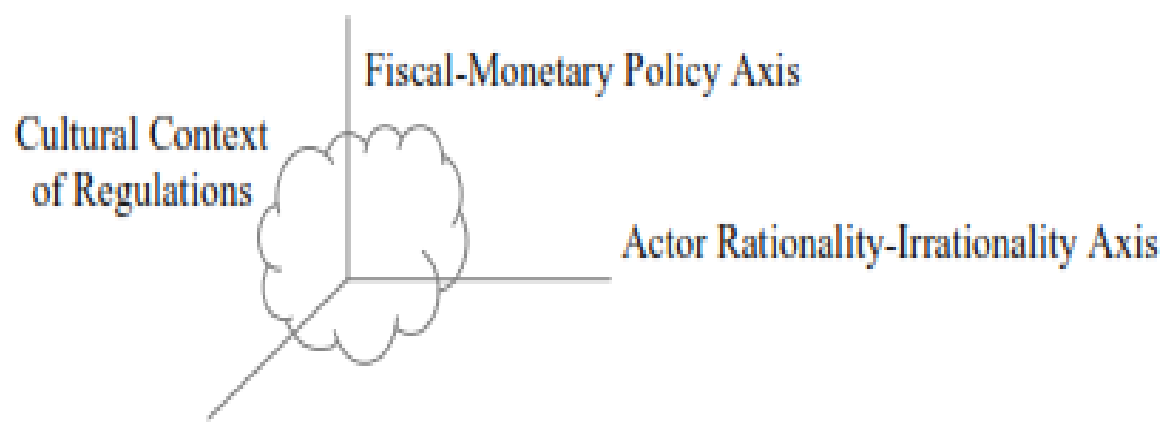

Systematic Risk-Reward Axis

Source: the authors 
Each part of the HEM is discussed in the paper, following a brief overview of the latest crisis in Section 2. As such, Section 3.1 addresses "Neoclassical-Keynesian Polarity in Policymaking", Section 3.2 includes "Individual Rationality and Aggregation", Section 3.3 presents "Systematic Risk-Reward of Capital Accumulation" and Section 3.4 outlines the "Cultural Context of Ineffective Regulations".

\section{Previous crisis explanations and why we need a better framework}

From 2007 to 2009 and afterwards, policymakers in industrialized countries struggled to evaluate the economic crisis that may have originated in their own advanced economies. Policymakers in emerging and developing economies were even more at a loss to react to this growing global catastrophe. Consider a sample of the range of explanations offered in the literature as causes of the 2007-2009 global crisis (Diamond and Rajan, 2009; Rose, Spiegel and Mark 2010; Allen and Carletti, 2010; Poole, 2010; Bean, 2010; Carmassi, Gros and Micossi, 2009; van Treeck, 2014; Yellen, 2011):

a) a domino effect of national crises world-wide led to capital flights for safety;

b) accommodative central bank policies distort pricing to avoid recession;

c) economic resources were miss-allocated to real estate in advanced economies;

d) currency exchange rates and savings were over-valued in emerging-economies;

e) exotic financial instruments directly or indirectly tainted bank balance sheets;

f) investments financed with short-term debt fail to price in long-term risk;

g) credit flows froze due both to fear of failure or opportunism for future gains;

h) international linkages generated by globalization spread contagion;

i) asset inflation and mortgage industry problems create a global housing bubble;

j) private sector securitization and analysis were inaccurate or dishonest; and

k) currency devaluations in emerging economies created a glut of investments.

If policymakers apply solutions for one cause without awareness of other factors, changes could exacerbate or prolong a crisis. For example, addressing (h) international linkages by closing off capital flows without recognizing the likely impact on (g) frozen credit flows, would mean a policy intended to cauterize suspected damage from linkages could halt needed credit infusions and further cripple economies.

Globalization also requires an awareness of policy impacts on and from the global economy, which has become so inter-related in the last century that few national economies are isolated. Cultural as well as economic factors became interconnected across borders; especially after the fall of the Soviet bloc and move toward capitalism by communist China (Allington, McCombie and Pike, 2012), economic development has been ushered in through cooperative international trade and market-based policies in most nations. In many ways, a transnational economy has emerged.

An important example of the inter-relatedness of national policies worldwide was the global crisis that seemed to originate in the United States in 2007 and swept from advanced economies to developing ones, before subsiding after 2009. Though its effects were devastating, the crisis posed a particular threat to newly-established market economies struggling to consolidate after the long, harsh period of communist control. In post-communist contexts, such as Romania, adequate public policies became critical, as these developing countries were subject to both multinational companies (or capital in general) fleeing the country (Barnes, Moldovan, and Pocsveiler, 2014, pp. 249-273) and, consequentially, decreases in the public funds (Moldovan, 2016, pp. 107-124) available to potentially implement anti-crisis policies. Yet, the devastating crisis became a thorny political issue in countries where the policy makers barely had a working knowledge of market economies and the global forces behind them. Thus policy makers in developing economies were even more ill-equipped than their similarly flustered counterparts in advanced and emerging economies to deal with the crisis.

Few researchers consider a holistic approach instead of case by case or one-dimensional explanations. For example, Evans (2010) proposes "five explanations for the international 
financial crisis", but most of his explanations are financial: "the widespread presence of perverse incentives; the over-expansionary monetary policy of the US Federal Reserve; the impact of global imbalances and a so-called 'savings glut' in developing countries; the extensive deregulation of the financial system since the 1970s; and the attempt to generate an increasing return on all forms of capital and the associated pressure on wages" (Evans, 2010). Claessens and Kose (2013, pp. 4-11) also view economic crises in financial terms, citing asset inflation and credit boom/bust cycles as the primary factors. And the US Financial Crisis Inquiry Commission (2011) focused on the financial narrative, largely ignoring policy or institutional failures and only marginally accounting for behavioral economics.

Economic research similarly offers narrow models, mostly limited to national or economic causes. Carmassi, Gros and Micossi (2009, p. 978) describe a "simple" cause as lax monetary policy and regulations encouraging excessive leveraging: "the factors that have contributed to the financial crisis in order to arrive at fairly simple policy recommendations".

Other narrow economic models include Allen and Carletti (2010) who insists a global housing bubble due to loose central bank monetary policies and a global glut in current account imbalances (arising from exchange rate manipulations) caused countries to seek both excess debt and debt holdings in foreign currencies. The authors defend mortgage banking as sufficiently regulated and inherently different from other industries, while harmful government policies and not private sector decisions world-wide are their cause and solution for crisis: Quantitative Easing is discouraged but the liquidation of large bank assets is encouraged during the crisis (Allen and Carletti, 2010).

Poole (2010) describes the excessively rapid reduction in the US Fed Fund rate from 5.25\% in August 2007 to 3\% in January 2008, ending in near-0\% rates by December 2009 as initiating the 6 months collapse of Bear Stearns, Lehman Brothers and AIG. Poole suggests government causes the crisis by employing a hodge-podge of solutions - first Buy Out then Bankruptcy then Bail Out. Bean (2010) presents an even simpler view: after years of a Great Moderation in global growth with limited inflation, the collapse was an inevitable "Minsky Moment" when economic success leads to excessive leveraging. While Bean (2010, p. 319) refers to a "multiplicity of factors", he offers few. In fact, Bean (2010) suggests that both the Great Moderation and the flows of capital from Emerging to Advanced Economies are unexplainable and notes the most central linkage seems to be a bi-directional causality between housing prices and international current accounts, possibly driven by a common underlying demand or excessive availability of credit.

For broader economic evaluations, Diamond and Rajan (2009) cite a flight to safety for capital fleeing various national crises and accommodative monetary policies by advanced-economy central banks. This led to an over-investment in real estate in the US through exotic financial vehicles that eventually tainted global balance sheets and froze credit flows worldwide as some banks feared insolvency and others horded cash for fire sales. Rose and Spiegel (2010) almost exclusively focus on linkages that spread contagions through "real" international trade channels and asset holding financial channels. Their statistical analysis concludes that, even though the US mortgage and financial industries are seen as both the epicenter and transmitter of the 2008 shock, global economies linked to the US economy fared much better than those less connected to the US. Rose and Spiegel (2010, p. 360) suggest that, even knowing in hindsight, the "timing and the epicenter of the 2008 crisis", any predictive "early warning system is statistically unlikely".

Bohle (2010) analyzes the post-Maastricht EU, arguing that the welfare state was not sufficiently sacrificed for monetary stability and the Maastricht Criteria concerning public deficits are not conducive to "catch-up development" in the periphery. Thus European elites could not leave the periphery behind and bending rules became the norm, causing instability. After the Greek fiasco, spillover effects became obvious and austerity was imposed on Eurozone members, but their efficacy was too limited and unfocused for a major global crisis. More sustainable growth within the EU may include: (1) debt restructuring supported by creditors and debtors, (2) wage formation 
linked more closely to productivity and inflation, and (3) private sector accountability for the destabilizing imbalances and asset bubbles it creates (Bohle, 2010).

Though some economist correctly anticipated the risks of a global crisis, none provided a full a priori prediction (Helleiner, 2011, p. 67). As such, this paper aims to provide a multiple perspective framework, promoting a more holistic view on the crisis and data-based simulations to provide a useful tool for understanding past crises and anticipating future ones. The main categories of the literature on economic crises analyzed in this paper include: (a) market mechanisms and institutional failures; (b) policy flaws or "inefficient" regulation; (c) irrational behavior; (d) systemic risks in capital accumulation; and (e) cultural biases such as mortgage obsessions or grasshopper-and-ant economies. Conclusions and potential future lines of inquiry are presented in Section 4.

\section{Results and discussions}

\subsection{Neoclassical-Keynesianism polarity in policymaking}

Two hundred years after Adam Smith, Keynes challenged the paradigm that "free market economies can function without a minder" (Krugman, 2009, p. 2-3) and called for active government intervention to address employment slumps through fiscal policies. Two decades later, neoclassical economists such as Milton Friedman shifted focus to monetarism where more limited government interventions use central banks to "keep the nation's money supply... growing on a steady path" (Krugman, 2009, p. 2-3). These two, the fiscal and monetary policy, form the first axis of a HEM.

The neoclassic movement assumes an efficient market, with self-regulated financial sectors, accurately pricing assets given adequate information, free from undue government interference. This view is balanced by New Keynesians who find an active role for government participation. Both approached generally accepted the rational functionality of "the efficient market hypothesis" due to "a great deal of statistical evidence" (Krugman, 2009, p. 4; Gregg, 2010, pp. 443-464). As the neoclassical economic paradigm spread from the US via globalization, the risk of a unitary world economic view increased (Assenza, Sokolíčková and Martynau, 2011) and an excessive trust in market mechanisms lead, just before the 2007 crisis, to "a general belief that bubbles just do not happen" (Krugman, 2009, p. 7) or that "this time is different because the United States are special” (Reinhart and Rogoff, 2009, p. 208).

The tug-o-war between Neoclassicism and New Keynesianism is likely to continue as one side "may have forgotten The General Theory and moved on" (Posner, 2009), while the other side argues there is "nothing distinctive in [knowing] that the sum of three negatives (administrative cost, allocative distortions, and unneeded uncertainty) is always negative ... The presumption remains: Government intervention is bad until shown to be good" (Epstein, 2010, p. 406).

Glyn (2007) shows how these two approaches working in tandem successfully met the crisis in capitalism after the 1950s and 1960s Golden Era. Speculation and high demand in the latter half of the $20^{\text {th }}$ century increased inflation as did lax monetary policies and automatic cost-of-living adjustments (COLAs) in Keynesian government programs. Labor movements and regulations constrained free markets and market capitalization fell. However, capitalism "got back on track" in the 1980s to 2000s led by US and UK growth combining strong fiscal and monetary policies: labor striking becomes negligible, inflation halted, real wages and profits increased, oil and other commodities leveled and automatic government spending was reduced. The external threat of nonmarket-based planned economies disappeared. International bodies such as the IMF blended monetary/fiscal policies of Neoclassical-Keynesian thought into a plan for Emerging and Developing economies worldwide. The argument is often made that the financial collapse in the US followed subprime mortgage defaults (Issa, 2010, p. 407; Taylor, 2009, p. 1); for a more detailed depiction of the events and policies regarding the financial crisis please visit the up to date account offered by The Federal Reserve Bank of St. Louis (undated). But this vulnerability was possible because of excessively lax (Neoclassical) Monetary Policies that encouraged low interest 
rates and exchange rates combined with excessively generous (New Keynesian) Fiscal Policies that inflated housing prices in the US, EU and UK and created savings in Asia. The two worked in tandem to produce a bubble that burst in 2008. This black-and-white policy approach was "loose fitting" during the pre-crisis period as (1) real interest rates fell in the US in 2007 (Taylor, 2009, p. 1) and (2) the flood of world savings fled to a safety in exotic higher-return mortgage back securities (Schwartz, 2009, pp. 23-24) whose complexity and government backing produced an overconfidence in investors to produce an opacity (Beachy, 2012, pp. 26-30). As such, policy makers around the world were blind-sided by Neoclassical-Keynesian regulations assumed to be in place to manage the global market economies.

\subsection{Individual rationality and aggregation}

A HEM also includes expectations of irrational behavior as policymakers benefit from a more holistic perspective of self-interested actors engaged in the necessary but difficult process of arbitrage. McDonald (2009, pp. 249-254) suggests that an analysis of the last financial/economic crisis must draw on behavioral economics, such as: "present bias, self-serving bias, 'new era' stories, money illusions, comparisons with reference levels and herding" (2009, p. 249). Kindleberger (1989) adds Hyman Minsky's model of crises to standard Keynesian and Monetarism perspectives (Kindleberger, 1989, p. 25) similar to the beneficial expectation of crisis in "Productive Paranoia" (Collins and Hansen, 2011) that prepares for extreme contingencies, including irrational expectations and speculation repercussions in markets. Modeling likely outlier events allows for innovative solutions in financial markets if the limits of rationality of financial actors are recognized to give policymakers tools to evaluate their impact on fiscal and monetary changes.

Events leading up to a crisis start with a displacement, changes in horizons, expectations, and behavior to bring opportunities for profit in new domains, while closing old ones, as in Schumpeter's "Creative Destruction" (1942). Firms and individuals accumulate savings or credit and try to take advantages of new opportunities while retreating from old domains (Kindleberger, 1989, pp. 17-18). This normal displacement facilitated the 2008 crisis when credit flows froze as lenders retreated from potentially insolvent companies and reserved resources to capitalize on likely fire-sales when insolvent companies collapsed (Diamond and Rajan, 2009).

Policymakers should expect these displacements as well as disruptions from events such as war or even democratically implemented regime changes. Displacements are generally understood to occur with some time lag before or after the event, and expectations play a large role in the impact of these exogenous events. Other displacements are endogenous, through speculative arbitrage and the expansion or contraction of money supplies through Central Bank rate changes and bond purchases, hard currency circulation exchanges, gold/silver ratio or exchange rate alterations, etc. (Kindleberger, 1989, pp. 46-49). Speculation develops in two stages during displacements: $\left(1^{\text {st }}\right)$ limited, rational investments are bought and $\left(2^{\text {nd }}\right)$ capital gains are realized by selling, by two groups of speculators - insiders (usually value driven) and outsiders (trading on perceptions of momentum). Arbitrage by both is necessary for markets to seek price equilibrium in a dynamic environment.

Policymakers also need to monitor the ways in which speculation leads to price fluctuations through euphoria (Kindleberger, 1989, pp. 19, 38-39). The euphoric episode is protected by those directly involved to sustain opportunities as actors resist those who resist Displacements and Disruptions (Galbraith, 1993, p. 11). Speculative euphoria can overheat prices where production increases or overtrading occurs (overtrading spreads across countries via arbitrage, imports and exports, capital flows, multinational holdings and psychological connections) encourages excessive over-estimations (Kindleberger, 1989, p. 19). Speculation that leads to irrational behaviors can produce a bubble (that will burst). After a speculative boom, insiders who accurately price the market take profits and sell at a greater ratio than outsiders who engage in momentum speculations tends toward a price leveling (Kindleberger, 1989, pp. 20-21). But instead of normal disruptions or displacements, this rebalancing can produce Financial Distress 
(Kindleberger, 1989, p. 112-120) that results in runs on banks and other losses of confidence in the market or system itself.

If speculators sense a possible rush for liquidity, falling prices leave some unable to pay margin loans and distress occurs as expectations adjust to a realization that the market will go no higher (Kindleberger, 1989, p. 21). Others causes of Distress include tight cash locally or abroad, rising interest rates, balance of payment deficits, bankruptcies, plateaued commodity prices (common in speculation), uncertain future expectations, poor harvest reports et cetera. Distress may be continuous or oscillate in a rhythm of its own, and even if the government knows more than speculators and makes a timely warning, historical accounts show that the warnings were often ineffective, except when the warnings were accompanied by restrictive/punitive measures (Kindleberger, 1989, pp. 109-112).

Although Neoclassicists and New Keynesians generally assume markets and individuals to be $a$ priori rational (Kindleberger and Aliber, 2005, p. 40), on occasions they can act in destabilizing ways that are irrational although each participant believes they are acting rationally. Policymakers must at least question how policies would interact with a market susceptible to such instances as (Kindleberger, 1989; Kindleberger and Aliber, 2005):

(1) Mob psychology where "group thinking" overwhelms market expectations so actors respond to the "herd mentality" and not underlying value;

(2) Simultaneous rationality and irrationality where individuals oscillate gradually at different stages between rational and irrational views;

(3) Mismatched actors where traders, investors, and speculators are each in different stages of the business cycle, making the overall market vulnerable to hysteria as asset prices change;

(4) Fallacy of composition where group behavior differs from the sum of individual behaviors (due to synergistic or toxic effects) or what may be rational for one becomes irrational for the market (group).

(5) Temporal lags (or the "tail wags the dog") where markets react to stimuli different from current events;

(6) Cognitive irrationality where investors analyze markets with inappropriate models or calculate prices based on missing critical information; and

(7) Moral irrationality where the market succumbs to bad actors or bad motives.

Policymakers often realize Distress and Disruptions occur after a specific signal (failure of a bank or firm, a defalcation, or a swindle; there is no "standard" time interval between distress and crash/panic) which precipitates a crisis, prices start to decline, bankruptcies increase and liquidation degenerates into panic. Distress persists and Revulsion/Discredit sets in (we differentiate between causa proxima - incidents that snap confidence, and causa remota - from speculation and extended credit) (Kindleberger, 1989, pp. 21-22). Crashes may be precipitated by inside (disc) information, accidental detonators, lags, backlogs or even government actions aimed at preventing further declines; not applying discipline allows credit markets to go further out of hand, while applying discipline in a harsh and abrupt way may induce a confidence collapse. Revulsion or panic feeds on itself until: (1) prices fall until it seems rational to move back into less liquid assets; (2) a circuit breaker limits declines by shutting down trades; or (3) a lender of last resort (government/central banks) assures the market that sufficient funds will be available (Kindleberger, 1989, p. 22). The policymaker's role after Revulsion is to calm anxieties and shorten the cycle after a crisis while accounting for other factors (population growth, exports, war) that influence the Recovery (Kindleberger, 1989, pp. 237-239). 


\subsection{Systemic risk-reward of capital accumulation}

A HEM also helps policymakers include two widely divergent views of systematic risks, both using one word: Revolution. Communists call for a Revolution to upend economies through central planning, and Capitalists expect a cyclical Revolution where markets move like planets. This divergence is important in views of capital accumulation. Marx saw it as an undesirable exploitation that destroys economic vitality as wealth accumulates and stagnates with very few exceptions. Schumpeter (1942) saw it as necessary to seize innovation and opportunities; accumulation of capital allows for "Creative Destruction" as the market improves: such as the elimination of buggy-making in favor of automobile-making; in this view, accumulated wealth is a fundamental and necessary good in economies. The benefit of a holistic evaluation is that policymakers can be aware of both potential risks and rewards of capital accumulation.

Engels (1843) proposes that competition between capitalists and workers results in monopolistic tendencies that require dramatic Revolution to correct. "If demand is greater than supply, the price rises and, as a result, supply is to a certain degree stimulated. As soon as it comes on the market, prices fall; and if it becomes greater than demand, then the fall in prices is so significant that demand is once again stimulated. So it goes on unendingly..." (Engels, 1843, p. 433). The pattern of expansion, overproduction, crisis and recovery become progressively worse and accentuate the conflict between classes, leading to total Revolution where "there is so much superfluous productive power that the great mass of the nation has nothing to live on, that the people starve from sheer abundance" (Engels, 1843, p. 435-436).

Polanyi (2001) offers a historical and somewhat moral perspective on free markets that economics is submerged in social relations. Wealth protects social status where distribution is ensured through reciprocity and not individual gains. For Polanyi (2001) capital accumulation is not an end but a means to social harmony. Then the mercantilist "free market" approach took over leading to fundamental social and moral changes where individuals were pauperized, facing starvation, and transformed into simple commodities that destroyed the "traditional fabric of society". The case of England during the eighteenth century serves as an example where the Industrial Revolution caused social dislocation that altered traditional settled populations and paved the way for a new free market capitalism requiring governments to intervene (Polanyi, 2001).

Discussing the allocation of state resources, O'Connor (1973) analyses the power relationship between the state and competitive sectors. O'Connor (1973, p. 6) draws from Marxism that capitalistic states must simultaneously fulfill two basic and contradictory functions: accumulation (the profitable accumulation of capital) and legitimization (maintaining social harmony). To do so, state expenditures include: (a) social capital expenditures for private savings, investment and consumption and (b) social expenses redistributing resources that may not be directly productive (O'Connor, 1973, pp. 6-7). Crisis occurs as social capital and expenses conflict, with social capital accumulating privately (and often at the behest of monopolistic interests) and being redistributed publicly for various social investments (O'Connor, 1973, p. 9). The inherent contradiction of capital accumulation is that even growth in the state sector (through state spending) still acts as a basis for growth in the private sector (O'Connor, 1973, p. 8). To ensure political legitimacy, the state allocates resources to those who suffer from economic disparity; thus the state does not have an incentive to avoid monopolistic tendencies. O'Connor sees the competitive sector as standing as a buffer between the state and monopoly sectors, but as less organized and less effective than either, as it competes within itself as well as with monopolistic forces and government regulations. The state caught between these two forces permanently increases public expenditures to both encourage capital accumulation and to absorb the shock from accumulation to legitimize its actions (O'Connor, 1973, pp. 13-32). As such, a crisis is to be expected by policymakers as a normal part of the "equilibriumization" of a dynamic economy. 


\subsection{Cultural context of ineffective regulations}

"Culture eats strategy for lunch". No matter what fiscal-monetary policies are implemented, despite the best assessment of rational-irrational behavior modeling and regardless of the struggles in capital accumulation, all regulations are implemented within a cultural sphere that can trump policy. The fourth dimension in which policymakers operate is their cultural or political environment along the three HEM axes. Examples include basic expectations in relationships or acceptance of certain levels of corruption that cloud regulation effectiveness. Analyzing the 20072009 financial crisis, Taylor (2009, p. 18) argues that in the US "while other factors were certainly at play, [...] government actions should be first on the list of answers to the question of what went wrong". The US government can be held accountable as its macro-economic policies caused the crisis by deviating from historical precedents and principles for setting interest rates (namely, the federal reserved lowered fund rates rapidly and farther than the norm), which had worked well for 20 years (Taylor, 2009, p. 2-3; Beachy, 2012 pp. 31-32). Contrary to US culture of egalitarianism, government (1) prolonged the crisis by focusing on liquidity rather than risk reduction (Taylor, 2009, pp. 9-15) and (2) exacerbated the crisis by providing aid to some financial institutions and creditors but not others, in an ad hoc way without a clear and understandable framework (Taylor, 2009, pp. 15-18). To "reinstate ... principles to follow to prevent misguided actions", Taylor (2009, pp. 18) proposes the reinstatement of expected norms such as setting interest rates as proved successful in the Great Moderation, clearly stating a rationale for interventions and providing a predictable framework for financial assistance.

Culture is even more clear in political positions against intervention expressed by economists and policymakers such as Rep. Ron Paul of the US Congress (2010, pp. 465-466) and Moore and Grimm (2010, p. 476). They argue that the US economy has been slowly drifting from "the free market economy (especially in the banking system due to the Federal Reserve) envisioned by the Constitutional framers and historical state-makers towards mixed economy... Central banks encourage more and more economic actors to make mistakes in the same direction (mainly toward taking more risks) at the same time, thus occasional bank and business failures are aggregated in a major recession or crisis" (Ron Paul, 2010, p. 469). The government has altered free markets to such a degree that it is changing the US from a culture of a "low-time preference" (deferred gratification) to a "high time preference" (instant gratification). The "inflationary conditions" and low interest policy of the Federal Reserve drove people to instant gains as long period savings were swept away by inflation (Paul, 2010, p. 471). And high taxes meant Savings (for retirement, education, or unexpected medical expenses) were captured by the state, so that in recession/crisis periods, people "welcome a bailout rather than lose their savings" (Paul, 2010, p. 471).

Undermining the long term economic preferences of a culture that previously provided social and economic organization at the individual level, the "economy of easy money and bigger government" reshaped the defining institutions of American life, the Constitutional setting as well as the social order. Self-reliance fostered over four centuries in American culture is being endangered as men and women seem encouraged to blame economic crisis on too much freedom and demand more government not only as protection against crisis but also as provision of basic needs... even as intervention is seen as part of the problem that caused the crisis in the first place (Paul, 2010, p. 472).

In the American context, given its history and relative values, a solution should aim at departing from economic regulation toward reinstating the "free market system" that would check "individual greed" by (1) re-orienting the time span toward longer-term gains to provide for individual future needs and (2) re-instating the possibility of investment losses as a deterrent to risky decisions. Bailouts and Federal Reserve lending creates perverse incentives as they reward failed banks and businesses and punish competitors who profit from sound decisions. Unfortunate, taxpayers that trusted risky financers and the government "get to foot the bill" (Paul, 2010, p. 473).

Beachy (2012, pp. 25-26) also mentions moral hazards as bankers were able to maximize gains after risky decisions while transferring losses to others. The evolutionary "survival of the fittest" 
model is being replaced by "too big to fail" that creates moral hazards. Taxpayers underwrite bad business and sweeping government interventions that began in early 2008 encouraged political corporatism where capital allocations are increasingly steered by Governments (Moore and Grimm, 2010, p. 485). A return to a more market-oriented economy is desirable as (1) "markets are the greatest engine of prosperity ever known"; "freedom and capitalism have been the greatest anti-poverty program in the history of humankind" and "government interference often makes crises in the financial markets worse" (Moore and Grimm, 2010, pp. 485-486).

Jackson (2010, p. 736) reveals "a moral-cultural malaise" in financial scandals as "Several causes of the present economic crisis, particularly financial innovation and complexity, excessive executive compensation, and neglect of moral hazard, are seen to be rooted in deep-seated moralcultural tendencies" (2010, pp. 738-739); cultural trends "cannot be resisted or reversed simply by increased law and regulation". They can only be addressed successfully by accounting for the "complexity of the relationship between ethics and economics and attune itself to the importance of trust, truth, and transparency" (Jackson, 2010, pp. 739). To understand crisis only via "mathematized economics" or increasing "legal regulation" is "barking up the wrong tree" (Jackson, 2010, 756) as long as the underlying cultural background is not addressed. Furthermore, freedom should not be ceded (by stricter legal regulation) but rather morally reformed on a "robust conception of moral virtue, human dignity, and the common good (Jackson, 2010, p. 778).

Kling identified the crisis as moral failure as "compensation structure for executives at financial institutions encouraged them to place their own and other firms at risk to reap short-term gains" and cognitive failure as "executives and regulators overestimated the risk-mitigating effects of quantitative modeling" (Kling, 2010, p. 507). Paulo (2011, pp. 5-6) also identifies a failure of regulation and financial supervision as one of the main causes of the crisis. Moral failures highlight distortions such as: (1) executive pay not tied to long term viability, (2) mortgage originators incentivized to make bad loans later integrated into structured financing securities and (3) rating agencies granting high ratings because they were paid by issuers (Kling, 2010, pp. 507508). The narrative of cognitive failure emphasizes the fact that key individuals were caught in a "utopian universe" as their faith in market mechanisms turned out to be unreliable. Such false beliefs included: "a nationwide decline in housing prices, having not occurred since the Great Depression, was impossible; increased home ownership rates were a sign of economic health; the use of structured finance and credit derivatives had reduced risk to key financial institutions; monetary policy only needed to focus on overall economic performance, not on asset bubbles; banks were well capitalized; and quantitative risk models provided reliable information on the soundness of mortgage-backed securities and of the institutions holding such securities" (Kling, 2010, p. 508). Policymakers failed to see the Crisis because they operated in this cognitive Cultural Sphere: "not because regulators lacked the will or the institutional structure with which to regulate, but because they shared with the financial executives the same illusions and false assumptions" (Kling, 2010, p. 508).

The cultural context must also recognize internal cultural differences during a crisis. Becker and Jäger (2010) discuss economic development in EU member states and current anti-crisis policies. Western Europe followed two models of accumulation: (1) in countries like the UK, Spain, Portugal, and France, financialization was usually doubled by high current account deficit, while (2) countries like Germany, Italy, Austria, and Sweden were characterized by extroverted accumulation with some elements of financialization. The overall trend in Central and Eastern Europe (CEE) countries (except Slovenia) is that key sectors are controlled by foreign capital, with two varieties of "dependent development": (1) the Visegrad group and Slovenia, accumulation used dependent industrialization while (2) the Baltic states and Eastern member countries (Bulgaria and partially Romania) achieve development by dependent financialization. Cultural differences also led to different policy reactions to the crisis: at first Western countries were concentrated on Monetary policies (stimulation of credit and restoration of inflationary trends vis-à-vis financial assets) but once this failed, Fiscal stimuli came to the fore. In CEE, export-oriented countries, took anti-cyclical measures while pre-cyclical measures dominated countries with dependent financialization (similar to how non-EU countries dealt with the crisis). 
Although the EU established rescue measures for banking, this was limited to the Eurozone and excluded most East European states, leading to a policy divide between the east and west, and more importantly, to a widening gap between the center and the periphery of the EU.

Strange (1998) analyzes public and private transnational debt from the 1980s and 1990s to see how international actors and foreign creditor states reacted. Her corollary is that although borrowing is economic, administering borrowing is political. Class structures and geopolitical factors influence anti-crisis policies nationally and internationally. Creditor governments after 1945 preferred uncertainty and $a d$ hoc solutions to address moral hazard. Rash investors were discouraged from making "unsafe" investments and debtors faced the possibility of "public humiliation" if they failed to return borrowed funds. Similar behavior can be observed even in the 1980s and 1990s due to the logic of the international political system.

Understanding cultural contexts reveals both unifying guiding principles and needs for diverse policy applications in a crisis. However, dealing with cultural factors (especially when trying to alter them) might be more problematic than it seems, if we take into account the "stability (and consistency) in time of organizational culture, even in the rapidly changing external environment" (Moldovan, 2012, pp. 34-39).

\section{Conclusion}

Designing crisis policies in the age of globalization requires a Holistic Evaluative Model (HEM) that accounts for multiple perspectives and realistic responses. To analyze a crisis and design policy solutions that can be implemented, a HEM employs a robust four-dimensional framework that includes (see again Figure 1): Actor Rationality-Irrationality on the x-axis, Fiscal-Monetary Policy on the y-axis, Systematic Capital Risk-Reward Analysis on the z-axis with Cultural Context as a cloud (background) factor.

Multiple constituencies in a crisis require policymakers to conceptualize the crisis and potential policy responses in terms of:

(a) How did the various factors interact in the crisis and what was their effect?

(b) How can decision makers account for conflicting views and present them publicly?

(c) Which factors can local policymakers actually attempt to influence?

(d) How can policy makers ensure future actions will not become similar failures?

(e) What might be the ripple effects of a crisis response in the areas of fiscal-monetary policy, economic behavior, capital accumulation and the particular cultural or political context?

Unfortunately, there are no "one size fits all" answers. Each factors makes its presence felt before, during and after a crisis and all have individual and aggregate effects. But policies must somehow account for, or at least acknowledge, the interplay of multiple factors, and this graphic HEM provides a tool to analyze these four dimensions to identify how a crisis forms a multi-vectored component in the local exposure to a global crisis. A multi-dimensional model provides several explanatory and clarifying tools that can relate to many different aspects of the impact of a global financial crisis, and the resulting clarity can provide an opportunity to create public policy insights to ameliorate an otherwise untenable situation.

The aforementioned model can be further improved by focusing on the relationships and interactions between each dimension, on their individual and combined effects; further research regarding this conceptual tool should benefit not only academia, but policy makers as well. 


\section{References:}

1. Allen, Franklin and Elena Carletti (2010), 'An overview of the crisis: Causes, consequences, and solutions', International Review of Finance 10(1): 1-26.

2. Allington, Nigel F.B., John S.L. McCombie and Maureen Pike (2012), "'Lack of balance, coordination and sustainability in economic development": China's growth and the 2007 financial crisis', Journal of Post Keynesian Economics 35(1): 45-63.

3. Assenza, Gaudenz, Zdenka Sokolíčková and Aliaksander Martynau (2011), 'The ideational background of the global economic crisis', Humanicus 6.

4. Barnes, D., Moldovan, O. and Pocsveiler, E. (2014), 'Regional partnerships, foreign investments and local economic development: A case study of Nokia in Cluj County, Romania', in Kovács, I.P. and Profiroiu, C.M. (eds.), Regionalisation and Regional Policy in Central and Eastern Europe, Bratislava: NISPAcee Press, 2014, pp. 249-273.

5. Beachy, Ben, (2012), 'A financial crisis manual. Causes, consequences, and lessons of the financial crisis', Medford: Global Development and Environment Institute Working Paper No. 12-06.

6. Bean, Charles (2010), 'Joseph Schumpeter Lecture: The great moderation, the great panic, and the great contraction', Journal of the European Economic Association, 8 (2-3): 289-325.

7. Becker, Joachim and Johannes Jäger (2010), 'Development trajectories in the crisis in Europe", Journal of Contemporary Central and Eastern Europe 18(1): 5-27.

8. Bohle, Dorothee (2010), 'The Crisis of the Eurozone', EUI Working Paper No. RSCAS 2010/77.

9. Carmassi, Jacopo, Daniel Gros and Stefano Micossi (2009), 'The global financial crisis: Causes and cures', Journal of Common Market Studies 47(5): 977-996.

10. Claessens, Stijn and Ayhan M. Kose. (2013), 'Financial crises: Explanations, types, and implications', International Monetary Fund WP/13/28.

11. Collins, James C. and Morten T. Hansen (2011), Great by choice: Uncertainty, chaos and luck - Why some thrive despite them all. New-York: Harper Collins.

12. Diamond, Douglas W. and Raghuram G. Rajan (2009), 'The credit crisis: Conjectures about causes and remedies', American Economic Review 99(2): 606-610.

13. Engels, Frederick (1843), 'Outline of a critique of political economy', in Marx \& Engels Collected Works, vol. III 1843-44. New York: International Publishers (1843, digitalized).

14. Epstein, Richard A. (2010), 'Why I will never be a Keynesian', Harvard Journal of Law \& Public Policy 33(2): 387-406.

15. Evans, Trevor (2010), 'Five explanations for the international financial crisis', Berlin Institute for International Political Economy Working Paper No. 08/2010.

16. Galbraith, John K. (1993), A short history of financial euphoria. Whittle Books/Penguin Books.

17. Glyn, Andrew (2007), Capitalism unleashed: Finance, globalization, and welfare. Oxford: Oxford University Press.

18. Gregg, Samuel (2010), 'Smith versus Keynes: Economics and political economy in the post-crisis era', Harvard Journal of Law \& Public Policy 33(2): 443-464.

19. Helleiner, Eric (2011), 'Understanding the 2007-2008 global financial crisis: Lessons for scholars of international political economy', Annual Review of Political Science 14: 67-87.

20. Issa, Darrell (2010), 'Unaffordable housing and political kickbacks rocked the American economy', Harvard Journal of Law \& Public Policy 33(2): 407-419.

21. Jackson, Kevin T. (2010), 'The scandal beneath the financial crisis: Getting a view from a moral-cultural mental model', Harvard Journal of Law \& Public Policy 33(2): 735-778.

22. Kindleberger, Charles P. (1989), Manias, panics, and crashes: A history of financial crises. New York: MacMillan ( $2^{\text {nd }}$ Edition).

23. Kindleberger, Charles P. and Robert Z. Aliber (2005), Manias, panics, and crashes: A history of financial Crises. Hoboken, New Jersey: John Wiley \& Sons ( $5^{\text {th }}$ Edition).

24. Kling, Arnold (2010), 'The financial crisis: Moral failure or cognitive failure?', Harvard Journal of Law \& Public Policy 33(2): 507-518.

25. Krugman, Paul (2009), 'How did economists get it so wrong?', New York Times, September 2, (2009) URL (consulted Aug. http://www.nytimes.com/2009/09/06/magazine/06Economict.Html 
26. McDonald, Ian M. (2009), 'The global financial crisis and behavioural economics', Economic Papers: A journal of applied economics and policy 28(3): 249-254.

27. Moldovan, Octavian (2012), 'Organizational culture under the microscope: Empirical analysis of a Romanian local authority', Managerial Challenges of the Contemporary Society 4: 3439.

28. Moldovan, Octavian (2016), 'Local revenue mobilization in Romania', 2016, European Financial and Accounting Journal 11 (3): 107-124.

29. Moore, Stephen and Grimm Tyler (2010), 'Straw Man capitalism and a new path to prosperity', Harvard Journal of Law \& Public Policy 33(2): 475-486.

30. O'Connor, James (1973), The fiscal crisis of the state. New York: San Martin's Press.

31. Paul, Ron (2010), 'The banks versus the Constitution', Harvard Journal of Law \& Public Policy 33(2): 465-473.

32. Paulo, Sebastian (2010), 'Europe and the global financial crisis. Taking stock of the EU's policy response - Explained in 10 Sheets', Robert Schuman Foundation, URL (consulted June 2016): http://www.robert-schuman.eu/en/dossiers-pedagogiques/crise-financiere/criseeconomique-mondiale-en-10-fiches-qe-200-en.pdf.

33. Polanyi, Karl (2001), The great transformation: The political and economic origins of our time. Boston: Beacon Press.

34. Poole, William (2010), 'Causes and consequences of the financial crisis of 2007-2009', Harvard Journal of Law \& Public Policy 33(2): 421-441.

35. Posner, Richard (2009), 'How I became a Keynesian', The New Republic, Sept. 23, URL (consulted June. 2016): http://www.tnr.com/article/how-i-became-keynesian?page=0,2.

36. Reinhart, Carmen M. and Kenneth S. Rogoff (2009), This time is different. Eight centuries of financial folly. Oxford and Princeton: Princeton University Press.

37. Rose, Andrew K. and Mark M. Spiegel (2010), 'Cross-country causes and consequences of the 2008 crisis: International linkages and American exposure', Pacific Economic Review 15(3): 340-363.

38. Schumpeter, Joseph (1942), Capitalism, socialism and democracy. New York: Harper \& Row.

39. Schwartz, Herman (2009), Subprime Nation. American power, global capital, and the housing bubble. Ithaca, New York: Cornell University Press.

40. Strange, Susan (1998), 'The new world of debt', New Left Review I(230): 91-114.

41. Taylor, John B. (2009), 'The financial crisis and the policy responses: An empirical analysis of what went wrong', NBER Working Paper No. 14631.

42. The Federal Reserve Bank of St. Louis (undated), 'Full Timeline', URL (consulted Aug. 2015): https://www.stlouisfed.org/financial-crisis/full-timeline.

43. The Financial Crisis Inquiry Commission (2011), The financial crisis inquiry report - Final Report of the National Commission on the Causes of the Financial and Economic Crisis in the United States, Washington: U.S. Government Printing Office.

44. Van Treeck, Till (2014), 'Did inequality cause the U.S. financial crisis?', Journal of Economic Surveys 28(3): 421-448.

45. Yellen, Janet L. (2011), 'Macroprudential supervision and monetary policy in the post-crisis world', Business Economics 46(1): 3-12. 